\title{
Research on the Cooperation of Emergency Response Based on the Exponential Random Graph Models
}

\author{
Li Zhouzhi \\ Harbin Engineering University \\ Harbin, China \\ 125863966@qq.com
}

\author{
Kang Wei \\ Harbin Engineering University \\ Harbin, China \\ kangwei9199@qq.com
}

\begin{abstract}
Recently, the domestic and foreign research results and management practice have shown the traditional government single management mode is transforming into the multi-subject cooperative governance mode, in the event of emergency response, the multi-subject organization and coordination is conducive to the effective integration of resources and unity and order of operation. Based on the governance theory and synergetic theory, this paper selects the "August 12 Tianjin Port Explosion Event" as the object of empirical study, uses the Exponential Random Graph Models, reveals the cooperative behavior and related relationship of organizations according to the specific structure of the network and then explores the cooperation motivation and cooperation mode between the organizations. The study has found that the nature and the level of the organization impact the cooperation motivation and cooperation mode between the organizations. Therefore, it is necessary to establish the inter-departmental cooperation mechanism and the neighboring dependency cooperation mechanism to improve the internal cooperation network of government, expand the cooperation among organizations, optimize the overall organization cooperation network, establish a collaborative platform led by government and participated by other organizations and construct the whole process of multi-organizational crisis cooperation to improve the efficiency of collaboratively governing crisis management.
\end{abstract}

Keywords-organizational cooperation; emergency response; Exponential Random Graph Models

\section{INTRODUCTION}

With social and economic development, all kinds of unconventional emergencies at home and abroad are emerging in an endless stream. In the last ten years, China has experienced a series of serious unconventional emergencies including the "Wenchuan Earthquake", "Ya'an Earthquake", "Trampling Event in Shanghai Bund" and "Tianjin Binhai New Area Explosion", unconventional emergencies are dynamic, complex and unpredictable, they are beyond the time boundary, the administrative boundary and the functional boundary, even beyond the scope of risk awareness of the subject and the controllable degree of response[1]. The high frequency of sudden events has become the new normal[2].Nongovernmental organizations as a force in disaster relief can not be ignored[3]. The response to unconventional emergencies requires cooperation among government, military and non- governmental organizations in different administrative regions as well as efficient organization of the overall coordinated response. The original government authority management mode has gradually been replaced by the mode of multi-subject cooperative governance, and the pattern for government and non-governmental organizations to participate in the emergency management work is forming. The society of our country present "risk symbiosis" situation, the government management of emergencies has limitations, the participation of non-governmental organizations, is a development trend of crisis management[4].

Based on the reality and theory, the Chinese scholars have made a lot of research on the cooperative governance and organizational cooperation of emergencies and public crisis, and the results mainly focus on the mode and the path of organization and cooperation, inter-domain and intergovernmental cooperation, scheduling and decision-making of emergency supplies, etc. In the process of emergency management, it is necessary to give full play to all social forces, encourage market organizations and social organizations to play a role, fundamentally reverse the "limitless government" problem in order to improve the efficiency of the whole social emergency management [5].

\section{ORGANIZATION AND COOPERATION IN EMERGENCY RESPONSE}

The core problem of the organization and cooperation is the process of integration and ordering of coordinative elements, and its essence is to maximize the mining of the advantages of each organization and elements, so that the whole emergency system can generate the overall functional effect as a result of complementary advantages. In this paper, the organization cooperation under the emergency is defined as a process in which many subjects including government, non-governmental organizations, business organizations and citizens take public emergencies as the core task, interact with each other, mutually trust, share responsibility, negotiate and cooperate based on autonomy and equality, and deal with the crisis in an interorganizational and highly efficient way through the mode of full information sharing and collaborative work in the interdependent environment. The cooperation is mainly public, cross-functional, interactive, formal and dynamic. 


\section{RESEARCH ON THE ORGANIZATION AND COOPERATION OF "August 12 TIANJIN PORT EXPLOSION"}

\section{A. Research method}

As a kind of important model in social network analysis, Exponential Random Graph Models is based on the assumption that dependence between the nodes is different, has experienced evolution from simplicity to complexity, and has been widely applied to various fields including social sciences, biological sciences. Compared with other research methods in social network analysis, the exponential random models can incorporate multiple levels of network structure variables into the research of network structure characteristics, and give the result of statistical test, which helps to reveal the social process of the whole cooperative network and the social behavior of nodes in the network from the micro level in a more comprehensive way [6].

\section{B. Data collection}

This paper takes the organization and cooperation of the August 12 Tianjin port explosion in 2015 as the subject for study and analyzes the cooperation between organizations from three levels: the cooperation among the government organizations, the cooperation among non-governmental organizations and the cooperation between the government and non-governmental organizations. A total of 192 nodes are selected and data mainly come from five sources: a. The official website of the government organization. b. The official website of non-governmental organizations. c. Authoritative traditional news portals. d. New media platforms, such as Sina micro-blog, Tencent micro-blog, etc. e. The contents of news conference on Binhai New Area hazardous materials explosion.

\section{Analysis of organizational collaboration network}

1) Government organization and cooperation network

In order to find the ideal model, we propose 3 models to find the optimal exponential random graph models.

TABLE I. PARAMETER ESTIMATION OF GOVERNMENTAL ORGANIZATIONS

\begin{tabular}{|c|c|c|c|c|}
\hline Model & Statistics & $\begin{array}{c}\text { Estimated } \\
\text { Value }\end{array}$ & $\begin{array}{c}\text { Standard } \\
\text { Deviation }\end{array}$ & t- statistics \\
\hline modle1 & Arc & -2.7742 & 0.075 & $0.078^{*}$ \\
\hline model2 & Arc & -5.1140 & 0.259 & 4.644 \\
\hline & Reciprocity & 5.2287 & 0.433 & 5.637 \\
\hline & In-2-star & 0.3075 & 0.135 & 8.575 \\
\hline & In-3-star & -0.0239 & 0.040 & 17.649 \\
\hline model3 & Arc & -2.1279 & 1.5009 & $0.0013^{*}$ \\
\hline & Reciprocity & 5.7757 & 6.5595 & $0.0029^{*}$ \\
\hline & 2-path & 2.1864 & 8.5662 & $0.0245^{*}$ \\
\hline & Transtivity & 0.9654 & 3.0613 & $0.0048^{*}$ \\
\hline & AoutS & 2.8648 & 0.6868 & 0.0482 \\
\hline & AinS & 0.4087 & 0.4265 & 0.0375 \\
\hline & A2P-D & 0.0416 & 2.17306 & $0.0017^{*}$ \\
\hline
\end{tabular}

Table I shows that in the three models, the absolute values of t-statistics in model 1 and model 3 are less than 0.1 , the absolute value of t-statistics in model 2 is more than 0.1 , therefore, give up model 2 and continue to carry on the goodness of fit test on model 1 and 3. The fitting results of the two models are shown in table II.

TABLE II. GOODNESS-OF FIT MODELS

\begin{tabular}{|c|c|c|c|c|c|}
\hline Model & Statistics & $\begin{array}{c}\text { Observed } \\
\text { Value }\end{array}$ & Mean & $\begin{array}{c}\text { Standard } \\
\text { Deviation }\end{array}$ & $\begin{array}{c}\text { Statist } \\
\text { ics }\end{array}$ \\
\hline modle1 & Arc & 188.0000 & 181.0780 & 12.211 & 0.567 \\
\hline & $\begin{array}{c}\text { Std dev in- } \\
\text { degree }\end{array}$ & 4.0000 & 3.6152 & 0.227 & 1.693 \\
\hline & $\begin{array}{c}\text { Std dev out- } \\
\text { degree }\end{array}$ & 3.8452 & 3.6544 & 0.229 & 0.833 \\
\hline model3 & Arc & 188.0000 & 207.5800 & 45.703 & -0.428 \\
\hline & Reciprocity & 80.0000 & 89.4620 & 21.726 & -0.436 \\
\hline & 2-path & 1.0000 & 0.8560 & 0.933 & 0.154 \\
\hline & Transtivity & 4.0000 & 3.3600 & 2.099 & 0.305 \\
\hline & AoutS & 212.8712 & 243.3811 & 73.558 & -0.415 \\
\hline & AinS & 209.8674 & 240.8107 & 74.390 & -0.416 \\
\hline & A2P-D & 127.7500 & 157.6068 & 70.331 & -0.425 \\
\hline & $\begin{array}{c}\text { Std dev in- } \\
\text { degree }\end{array}$ & 3.9483 & 4.5288 & 0.807 & -0.719 \\
\hline & $\begin{array}{c}\text { Std dev out- } \\
\text { degree }\end{array}$ & 4.0598 & 4.5038 & 0.789 & -0.563 \\
\hline
\end{tabular}

The absolute values of t-statistics of all the parameters in the goodness of fit are less than 2, and the standard deviation of in-degree distribution and standard deviation of out-degree in model 1 are higher than that in model 3, from the goodness of fit, model 3 is better than model 1, so we accept model 3 .

As can be seen from table I, the estimated parameters of the interactive 2- path of the network are 2.1864 and significant, which shows that there is network node in the government cooperation network that acts as the "intermediary organization" and has a positive effect. Such as, "rescue headquarters", "Tianjin municipal government" and other nodes shoulder the task of collecting and providing disaster relief resources in the network and promote the rescue. The estimated parameters of the network component Transtivity are 0.9654 and the effect is significant, which indicates that the grade closed path in the network is obvious. It is particularly reflected in the close reciprocal relationship between the upper and lower levels of the government organizations, and local hierarchical network is available. In the response to the event, the organization and command system of the upper and lower linkage integrating the national, municipal, district levels is implemented. Among them, "command by the State, arrangement by city and implementation by district", and different levels of problems shall be dealt with according to different functions. At the same time, through AoutS and AinS statistic results, it can be seen that convergent and expansion of most individual actors in the network is not significant. It is mainly reflected in the relatively sparse cooperation between various functional departments, local governments at all levels within government organizations in the cooperative network. Network component A2P-D parameter values are positive and significant, which indicates that there are still multiple leaders in the cooperative network. Such as the "Tianjin Municipal Public Security Bureau", "Tianjin Health and Family Planning Commission", the treatment shall be under the dual leadership, and it shall both accept the task assigned by Tianjin municipal government, but also accept the command from the working group of the State Council. 
2) Non-governmental organization network

TABLE III. PARAMETER ESTIMATION OF NON-GOVERNMENTAL ORGANIZATIONS

\begin{tabular}{|c|c|c|c|}
\hline Statistics & $\begin{array}{c}\text { Estimated } \\
\text { Value }\end{array}$ & $\begin{array}{c}\text { Standard } \\
\text { Deviation }\end{array}$ & t- statistics \\
\hline Arc & 3.01288 & 0.3574 & $0.0027^{*}$ \\
\hline Reciprocity & 0.5425 & 0.534 & $0.0043^{*}$ \\
\hline 2-in-star & 1.4623 & 0.1493 & $0.0182^{*}$ \\
\hline 2-out-star & -0.3759 & 0.5831 & 0.0026 \\
\hline 2-path & 0.0948 & 0.1098 & $0.0343^{*}$ \\
\hline Transtivity & -3.1341 & 0.9463 & 0.0751 \\
\hline isolates & 9.2647 & 0.5164 & $0.0098^{*}$ \\
\hline AT-D & 9.4653 & 1.4977 & 0.0753 \\
\hline AT-U & 15.9740 & 1.2416 & $0.0467^{*}$ \\
\hline
\end{tabular}

As can be seen from table III, the estimated parameters of network components 2-in-star, 2-out-star, AT-D and AT-U are $1.4623,-0.3759,9.4653$ and 15.9740 respectively. Among them, the results of 2-in-star and AT-U are significant, which shows that the individual actors in the network have obvious convergent. Such as "China Siyuan Foundation for Poverty Alleviation" aggregates most of the NGOs resources to ensure fund rescue operations can be carried out in an orderly and efficient way. The estimated parameter of network component 2-path is 0.0948 and significant, which indicates that there is a network node with intermediate nature in the non-government network. Such as the "China Red Cross" distributed the integrated resources from other regions of the country to the Tianjin Municipal Red Cross, and then the Tianjin Municipal Red Cross issued them to various settlements. In addition, different from the government organizations and cooperation network, the estimated parameter of the network component Transtivity is -3.1341 , and the effect is not significant, which shows the relationship among the actors in the nongovernmental organizations is mainly based on equal negotiation, and there is no obvious structure of local hierarchical network. The estimated parameter of the network component isolates is 9.2647 and significant, which shows that in the absence of a government organization node, there were some isolated points in the non-governmental organization network, That is, some actors in non-governmental organizations directly related to the government organizations, and did not establish cooperative relations with other nongovernmental organizations. Such as, "Hongkong Federation of Trade Unions Relief Charity Fund".

3) The whole network of organization and cooperation

TABLE IV. PARAMETER ESTIMATION OF THE OVERALL NETWORK

\begin{tabular}{|c|c|c|c|}
\hline Statistics & $\begin{array}{c}\text { Estimated } \\
\text { Value }\end{array}$ & $\begin{array}{c}\text { Standard } \\
\text { deviation }\end{array}$ & t- statistics \\
\hline Arc & -4.5799 & 0.4622 & $-0.0076^{*}$ \\
\hline Reciprocity & 2.1487 & 0.2238 & $0.0169^{*}$ \\
\hline 2-path & -1.0208 & 0.4031 & $0.0404^{*}$ \\
\hline Cyc-traid & -0.3728 & 0.3887 & 0.0334 \\
\hline AinS & 0.0403 & 0.3031 & $0.0617^{*}$ \\
\hline AoutS & 0.2680 & 0.3770 & -0.0423 \\
\hline AT-T & -2.5518 & 1.3145 & 0.0656 \\
\hline A2P-T & 1.1092 & 0.4082 & $0.0638^{*}$ \\
\hline A2P-D & -0.1107 & 0.1125 & $0.0016^{*}$ \\
\hline A2P-U & 0.0679 & 0.0803 & $0.0232^{*}$ \\
\hline
\end{tabular}

As can be seen from table IV, the estimated parameters of network components AinS and AoutS are 0.0403 and 0.2680 respectively, and the AinS result is significant, AoutS result is not significant, which indicates that the network has a relative concentration. The estimated parameters of network components 2-path and A2P-T are positive and significant, which indicates that there exist effects of structural holes in the cooperative network, and some of the actors play the role of "intermediary bridge". Such as "China Charity Federation", "China Red Cross" and other non-governmental organizations provide material support for Tianjin. The estimated value of network structure Cyclic-traid parameter is negative and not significant, but the estimated value of Reciprocity parameter is positive and significant, indicating that the interaction between the actors in the network is obvious, but there is a lack of circulation in cooperation. In particular, the one-way flow of information, personnel and material resources between the government and non-government organizations affects the speed and quality of resource flow and integration to a certain extent. The measured results of network component AT-T are not significant, which indicates that there is no obvious level path closure in the cooperative network between the government and non-governmental organizations. Cooperation in emergencies is mostly consultative cooperation without grade characteristics. In addition, the measured results of the network components A2P-D and A2P-U parameter show that there are no two actors directly contacting each other two actors who will cooperate because they are related with the same actor. The uncertainty of the cooperation between the nodes reflects the instability of the overall network structure.

\section{CONCLUSION AND SUGGESTION}

There is large difference in terms of status and influence of the government and non-governmental organizations in the emergency organization and cooperation, and there are still many problems to be solved in the cooperative network.

First, improve cooperation within the government organization. Under the current system in China, the crisis management is of low efficiency and high cost. To improve cooperation among government organizations, what can be taken into account is to strengthen cooperation between the various functional departments, establish a permanent crisis management center and a non-permanent joint committee of the cross functional departments. Strengthen cooperation among local governments at all levels in the adjacent areas, construct a disaster emergency resource cooperation network and share the risk and cost of public crisis.

Secondly, optimize the internal cooperation of nongovernmental organizations. At present, the non-governmental organizations in China in the star pattern of decentralization. To a certain extent, it causes the non-governmental organizations to get involved in the rescue in a disorderly way. In order to better play the advantages of non-governmental organizations, to improve the efficiency of the use of private resources, a unified platform can be established that is directly responsible for the coordination and deployment of all resources of non-governmental organizations. Nongovernmental organizations with the same function can expand homogeneity cooperation, reduce similar functional 
organization structure and maximize the total utility of resources through integrating and focusing their resources.

Finally, cooperate between the government and nongovernmental organizations. After the events of public crisis occur, there are problem due to the lack of effective communication platform and information integration mechanism between the government and NGOs, such as, emergency congestion, uneven distribution of resources, and to a certain extent, they affect the progress of the rescue. Therefore, for improvement of collaborative governance in the public crisis between non-governmental organizations and government organizations, first of all, establish the collaborative platform which is led by government and participated by non-governmental organizations, and coordinate the extensive cooperation between nongovernmental organizations and governmental organizations in the areas of information, personnel, materials, etc. Take effective preventive measures to reduce the possibility of crisis.

In this paper, the problem of cooperative governance in public crisis management is the comprehensive research with the combination of qualitative and quantitative analysis in this field, and there are some limitations. It only analyzes and explains the specific structure of the network and has not established the specific model of organization and cooperation network. In summary, the conclusions and recommendations requires further research and improvement.

\section{REFERENCES}

[1] William L. Waugh, "Collaboration and Leadership for Effective Emergency Management," in Public Administration Review, vol.12. pp.131-140, 2006(In Chinese)

[2] Xu Songhe,Han Chuanfeng and Meng Lingpeng "Dynamic Structural Analysis and Reconstruction Strategy of China's Emergency Management System," in China Soft Science, vol.295. pp.20-28, 2015.(In Chinese)

[3] Dong Xiaosong, "Construction of emergency command and coordination mechanism for major natural disasters," in Theory and Reform, vol.211.pp.4 -7, 2016.(In Chinese)

[4] Zhang Haibo and Tong Xing, "Structural Change in China's Emergency Management: T heoretical Generalization," in Social Sciences in China, vol.37. pp.77 -98, 2016.(In Chinese)

[5] Xue Lan and Liu Bing, "The new challenge of the emergency management system and its top design," in Journal of China National School of Administration, vol.82. pp.10-14, 2013.(In Chinese)

[6] Ren Yike, Li Shuzhuo and Du Haifeng,, "Analysis of social network structure of peasant workers," in Journal of Xi'an Jiaotong University, vol.91. pp.44 -51, 2008.(In Chinese) 